\title{
College Ideological and Political Theory Course Teaching Using the Podcast-in the Perspective of Shaping Students' Subjectivity
}

\author{
Yong-Hong Zhang
}

\begin{abstract}
Using podcast module in the college ideological and political theory teaching can stimulate students' enthusiasm to participate in the ideological and political course, make the ideological and political course more interesting, and help the teacher grasp the students' ideological trends more timely. To implant podcast module in the ideological and political theory teaching, the teacher should give full play to students' subjectivity in the making of podcast and make the necessary guidance.
\end{abstract}

Index Terms-Ideological and political theory course, podcast, student, subjectivity.

\section{INTRODUCTION}

Since the second half of 2004, Podcast as a new digital broadcasting technology has been increasingly popular on the internet. With the aid of podcast, people can release their self-made audio or video information through the network, and let others listen to or watch it timely on the internet, so as to realize the sharing of sound and video information. As a new thing which makes one's personality publicized and highlights fashion, the podcast contains grassroots public expression culture which highly fits the demands of college students, especially with the construction of mobile platform represented by $3 \mathrm{G}$ technology, the podcast is gradually becoming an important information channel and social communication form to college students. College teachers should try to fully understand the characteristics of podcast and its teaching effects, and positively develop and utilize this new curriculum resource. This article, from the perspective of shaping students' subjectivity, deals with the using of podcast in college ideological and political theory course teaching.

\section{EFFeCT OF THE USE OF PODCAST ON THE COLLEGE} IDEOLOGICAL AND POLITICAL THEORY COURSE TEACHING

The college ideological and political theory course is the main channel of conducting ideological and political education to college students. In recent years, various universities have reformed teaching methods and means of the ideological and political theory course and improved the teaching effectiveness to a certain extent. But in the present

\footnotetext{
Manuscript received March 9, 2013; revised June 20, 2013. This work is supported in part by Planning Project of Chongqing Education Science for the year 2012(2012-GX-026).

Yong-Hong Zhang is with School of Marxism, Research Center for Marxist Theory, Southwest University, Chongqing 400715 China (e-mail: zyyhhh867@sohu.com).
}

case, there are still some problems with the ideological and political theory course teaching which make the teaching effect hard to reach the ideal state. Generally speaking, more priority is given to teaching by teachers, while students' participation in the course is still not satisfactory. In addition, classroom teaching by some teachers is not interesting enough; some teachers are sticklers for the course conspectus and teaching materials while dot not know much about the actual problems students are concerned about, so that their teaching lacks accordance and is difficult to "pull at students' heartstrings". All of these are affecting students' display in subjectivity and the teaching effect of the ideological and political theory course. As a new type of "compensatory media", the unique characteristics of the podcast play an active role in breaking through the above-mentioned bottlenecks.

\section{A. Podcast Promotes Students' Participation in the Ideological and Political Theory Course Teaching}

The traditional ideological and political theory course teaching is often confined to the transmission of sounds and words and static graphic symbols, by contrast, the podcast, with both audio and video multimedia forms, can provide a more complete audio-visual symbol carrier. Those publishers can realize free video expression and communication on the network full-time and interactively makes the podcast in essence a democratic information communication platform. In addition, based on the unique combination mode of podcast and mobile digital player, which makes this communication done anywhere and anytime, the audience is no longer purely static passive information receiver, but the active information disseminator and critics. The use of podcast is essentially a public communication behavior people make through the audio-visual media. Participation, the predominant feature of the podcast, forming the display of self-consciousness and the construction of podcast personality, contributes to a "podcast -audience" interactive ideographic shaping process [1].This characteristic makes the use of podcast in the ideological and political theory course teaching not only helpful to students to actively think about the social reality, but also helpful in making them put in enough enthusiasm in the course and achieve a team interaction and mutual learning effect in the free choosing of topics and free statement. In practice, this learning style embodied in the form of team cooperation to solve key problems of the course can largely make up for the lack of willingness of students to participate in class activities and bad teaching effect in the previous teaching practice. 


\section{B. Podcast Can Spice up the Ideological and Political Theory Course Teaching}

The vivid immediacy, imagery of the podcast symbol can make the podcast please people's senses and become completely a perceptual "hot media" [2]. It's easy sensibility reduces the stiff feeling of traditional cold media such as word texts. In the cognitive process, this kind of "hot media" does not need active imagination and the participation of independent judgment needed when decoding words. Thus, seeing and hearing become very easy, which makes people easy to have a crush on it and has the attraction of the ideological and political theory course teaching guaranteed. Moreover, public pleasure is created in a meaning-producing way, and the podcast provides a new technical condition for this production. As the podcast belongs to a UG (user generate) mode, the public can not only produce their own meaning and pleasure in the interpretation of the media text, but can transform the text and produce their own text according to their own understanding and need. Therefore, the individual happiness changes from the "interpretative one" to the "productive one", and the process of meaning production is also transformed into the process of changing the text [3].In view of this, every successful podcast can give students a great sense of accomplishment and the meaning of value production both interpretatively and productively, with the result that it improves the attraction of the ideological and political theory course teaching and reverses the rigid moralistic impression of the traditional course teaching.

\section{Podcast Becomes the New Channel for College \\ Teachers to Grasp Students' Ideological Actions}

With the development of network culture, increasingly diverse social conscious nesses have penetrated into the podcast, and a expression space with a strong touch of social grassroots is gradually formed [4]. It is this cultural form with" social sensitivity" that makes the new generation of college students have the opportunity to express their social cognition, thus revealing their attitudes and judgments towards the problems and phenomena with which the ideological and political theory course is associated. Through the podcast, teachers could know the students' thoughts quicker and better, thus educating and leading students more properly and timely.

\section{The Way to Implant Podcast Module In THE College IdeOlogical ANd Political TheOry CoUrSe TEACHING}

\section{A. Take Students as the Main Body in Podcast Making}

The key to implant a podcast module in the college ideological and political theory course teaching is the production of podcast. Both teachers and students are the main bodies of teaching activities. Of course, this holds true for podcast production, too. In the concrete practice, students as the main body of podcast production should especially be focused on, because, if teachers are the only producers and publishers of podcast, it only means that the ideological and political theory courses extend to the virtual network space with the aid of podcast, which, for students, has no substantial difference from the traditional teaching mode except that it has some novelty in the sense of a instrument. As the subject of rights in the modern sense, college students should enjoy media access and transmission rights. In the process of podcast making, college students can use audio-visual materials to become qualified as" a coder", which is hard to achieve in a traditional classroom mode, so as to make their wish for "self-actualization" realized to a certain extent, and have them come to think about the social reality positively and express their ideas openly.

Podcast production is normally faced with two restrictive factors: supporting software and hardware equipment's required by the podcast technology itself, and the video file preparation technology needed by the podcast. Therefore, teachers should encourage students to make full use of the mobile phone's camera function and rich internet multimedia resources to solve the problem of instrument with which to collect materials; to use free editing soft wares on the network to make audio and video clips and post production. As for the specific equipment, public courses such as computer, network could be considered to make better use of the computer platform, and realize sharing and win-win of resources. With the aid of team members, some constraining bottlenecks in podcast making such as students' ability to participate in and software and hardware restricts could also be solved to a certain extent through the sharing of software and hardware and ability complementary. And the team cooperation mode is of help to cultivating team consciousness of students with prominent personality.

\section{B. Regulate and Guide the Podcast Content}

Generally speaking, the podcast content produced and released mainly by students, which is usually "micro content" with low cost or even no cost for the user, is different from the "macro content" of the traditional mass media [5].The personal characteristics of the micro content don't often cohere with "grand" propositions or "big words" of the ideological and political theory course. Therefore, teachers should make necessary norms and guidance for the content of podcast and ask students to create podcast content serving the subject of the ideological and political theory course. Teachers can set up podcast topics corresponding to those of the ideological and political theory course and entertaining students, to achieve the effective interaction between teachers and students in the "theme setting- content creation podcast show" flowing order. In this process, the teacher could get rid of the traditional image as a pure sender of information and takes on the image of decoding information, besides as the producer and "the coder" of podcast [6].This role is more likely to convince college students and help them become the leading part of class, so as to best reinforce their sense of identity for topics of the ideological and political theory course teaching. Of course, in specific content construction and expression, teachers should give students some independent creative space to mobilize their participation enthusiasm and initiative, and finally lead them to understand and internalize the content of the course teaching. What needs to be stressed is that due to the openness of the podcast itself, there exist inevitably external public interventions, which may affect the content and quality of the podcast. So, it's appropriate to make a restriction on podcast participation. It would perhaps be more 
advantageous to the ideological and political theory course teaching to have the podcast platform installed in the interior space of the campus LAN.

\section{Introduce Podcast Content into Classroom and Make Subsequent Perfection}

The ideological and political theory course is usually taken in the classroom, while the podcast relies on the internet and storage equipment. Thus based on the difference in space, a right communication channel must be found to make the classroom and podcast effectively butt. Firstly, this requires that students prepare the podcast content according to the class arrangement and related themes, and put the finished podcast on the special web space, which, after being examined by the teacher, is to be opened to the public. Secondly, the teacher needs to ask students to familiarize themselves with the podcast content before the class begins and link to the specific podcast content directly in classroom teaching, and give a real-time analysis, discussion and explanation on the content. Finally, as a homework, students need to be required to continue to supplement and perfect the podcast content and enrich the material database for future students' learning and reference.

\section{CONCLUDING REMARKS}

As a new form of media, the podcast shows growing social influence. For college students in the "E" era, the podcast fits their needs in tool's sense, and becomes a powerful platform in revealing their own personalities and reinforcing their own images. Therefore, introducing the podcast into the college ideological and political theory course teaching could form a media means echoing students' psychological demands and urging them to express their own thoughts and values, thus favoring the teachers' guidance in students' thoughts and actions.

\section{REFERENCES}

[1] B. Chen, "Analysis on Podcast Performance and Its Transmission by the Audience," Southeast Communication, vol. 8, pp. 34, August 2008.

[2] L. P. Tang, "New Change in Audio-visual Media: a Research on the Podcast Network Communication," Ph.D. dissertation, Sichuan Univ., Chengdu, 2007.

[3] H. Zhang, "Analysis on the Cultural Significance of Podcast," China Youth Research, vol. 6, pp.18-20, June 2007.

[4] C. Evans, "The Effectiveness of M-learning in the Form of Podcast Revision Lectures in High Education," Computers \&Education, no. 50, pp. 491-498, 2008.

[5] W. Zhang, "Podcasting Application in Network Education," Introduction of Educational Technology, no. 9, pp. 8, 2006.

[6] C. Sutton-Brady, "The Value of Using Short-Format Podcasts to Enhance Learning and Teaching," ALT-J, Research in Learning Technology, vol. 17, no.3, pp. 32, 2009.

Yong-Hong Zhang was born on Oct. 26, 1971, in Shanxi, China. He is an associate professor of Southwest University, Chongqing, China and the author of many articles on social ideological trends and methodology. 